\title{
ANALISIS KEUNTUNGAN USAHA RUMAH KAYU CV TUMOU PRATAMA DI KELURAHAN WOLOAN 1 KECAMATAN TOMOHON BARAT
}

\author{
Andrey Dymitri Makawekes \\ Grace Adonia Josefina Rumagit \\ Celcius Talumingan
}

\begin{abstract}
This study aims to analyze the profits of CV Tumou Pratama's wooden house business in Woloan 1 Village, Tomohon Barat District. This research was conducted for 3 months, starting from September to November 2018. The data used are primary data and secondary data. Primary data was obtained from direct interviews with wood house business owner CV Tumou Pratama (one person). While secondary data was obtained from several sources are the Central Bureau of Statistics, books available at local bookstores and the internet such as google cendikia to access articles from various scientific journals and theses from other universities related to the topic of this research, especially concerning profit analysis. The results of the study indicate that CV Tumou Pratama's wooden house business during the period January 2017 to December 2018 is profitable, both in total and based on type and size (m2). The highest profit per $m 2$ is Rp. 1,003,554, - obtained from Medium Type Wooden Houses $(70 \mathrm{~m} 2)$ compared to Small Type Wooden Houses $(36 \mathrm{~m} 2)$ of Rp.978,099; Large Type (112 m2) of Rp.698,074, -; and Extra Type (198 m2) of Rp.576.352.- *inkdeprm*
\end{abstract}

Keywords: Profits, Wooden House Business, CV Tumou Pratama, Tomohon City

\begin{abstract}
ABSTRAK
Penelitian ini bertujuan untuk menganalisis keuntungan usaha rumah kayu CV Tumou Pratama di Kelurahan Woloan 1 Kecamatan Tomohon Barat. Penelitian ini dilakukan selama 3 bulan, mulai dari bulan September sampai bulan November 2018. Data yang digunakan adalah data primer dan data sekunder. Data primer diperoleh dari wawancara langsung dengan pemilik usaha rumah kayu CV Tumou Pratama (satu orang). Sedangkan data sekunder diperoleh dari Badan Pusat Statistik, buku-buku yang tersedia di toko buku lokal dan internet seperti google cendikia untuk mengakses artikel dari berbagai jurnal ilmiah dan skripsi dari perguruan tinggi lain yang berkaitan dengan topik penelitian ini terutama menyangkut analisis keuntungan. Hasil penelitian menunjukkan bahwa usaha rumah kayu CV Tumou Pratama selama periode Januari 2017 sampai Desember 2018 menguntungkan, baik secara total maupun berdasarkan tipe serta ukuran (m2). Keuntungan tertinggi per m2 sebesar Rp.1.003.554,- diperoleh dari Rumah Kayu Tipe Sedang (70 m2) dibandingkan dengan Rumah Kayu Tipe Kecil (36 m2) sebesar Rp.978.099; Tipe Besar (112 m2) sebesar Rp.698.074,-; dan Tipe Ekstra (198 m2) sebesar Rp.576.352.- -jikk+eprm*
\end{abstract}

Kata kunci : Keuntungan, Usaha Rumah Kayu, CV Tumou Pratama, Kota Tomohon

\section{PENDAHULUAN}

\section{Latar Belakang}

Sektor industri memegang peranan strategis dan harus mampu membawa perubahan mendasar dalam struktur perekonomian Indonesia. Hal ini berarti bahwa sektor industri di dalam perekonomian nasional berperan sebagai motor penggerak utama bagi pertumbuhan sektor-sektor lainnya lewat keterkaitan produksi ke belakang (backward production linkage) maupun ke depan (forward production linkage) (Amril, 2003). 
Pertumbuhan sektor industri akan mampu menciptakan lapangan kerja serta memperluas kesempatan kerja, menyediakan kebutuhan barang dan jasa, meningkatkan serta menghemat devisa, mendorong pembangunan daerah, meningkatkan serta memeratakan pendapatan masyarakat dan mengentaskan kemiskinan (Arifin, 2012).

Proses industrialisasi dalam pembangunan industri juga penting dalam mendukung berlangsungnya perubahan tata nilai masyarakat dan pranata sosial yang lebih dinamis dan berkualitas (Supardi, 2003). Dimana perubahan kehidupan ini dampak dari meningkatnya kegiatan sosial maupun kegiatan ekonomi dari masyarakat disekitar industri. Pengembangan sektor pertanian dalam mendukung industrialisasi didasarkan pada pendekatan agribisnis, termasuk agroindustri yang dapat memperkuat kaitan mata rantai produksi, penanganan pasca panen, pengolahan dan pemasaran untuk meningkatkan nilai tambah hasil-hasil pertanian pada umumnya, maupun produk pangan pada khususnya.

Salah satu agroindustri di Provinsi Sulawesi Utara yang semakin menunjukkan perkembangan menggembirakan dan berpotensi untuk dikembangkan lebih lanjut adalah industri rumah kayu Minahasa. Sejak ditetapkan pemerintah daerah sebagai kawasan pengrajin rumah kayu, perkembangan industri pembuatan rumah kayu Minahasa atau sering disebut rumah kayu Woloan membawah perubahan terhadap kehidupan masyarakat sekitar industri karena sebagian besar pekerja/pengrajin rumah kayu adalah masyarakat Woloan. Hal ini dapat dilihat dari eksistensi para pengusaha rumah kayu tradisional Minahasa yang diproduksi di Tomohon, kini di ekspor ke-30 negara yang tersebar di Afrika, Asia hingga Eropa. Ekspor rumah kayu Minahasa dapat terwujud karena pembeli luar negeri percaya selain motif menarik, juga kualitas pembuatan rumah yang semain baik dari waktu ke waktu (Kompas, 13 November 2018).

Industri rumah kayu Woloan ini tampak menjanjikan karena memiliki berbagai keunggulan. Dari segi ekonomi, rumah kayu ini harganya relatif murah tergantung dari model dan ukurannya. Disamping itu, dengan model yang dapat disesuaikan dengan pesanan konsumen dan sistem bongkar pasang (knock down) membuat rumah ini sangat fleksibel memungkinkan rumah ini dipasang dan dipindahpindahkan ke tempat yang diinginkan. Dari segi konstruksinya, terutama dengan rangka yang saling bertumpuh dan kait mengait membuat rumah ini tahan terhadap gempa serta tiang rumah yang tingginya 2,5 sampai 3 meter menjadikan rumah ini cocok untuk daerah rawan bencana. Dengan demikian rumah kayu ini dapat menjadi alternatif bagi rumah sangat sederhana dan rumah lainnya yang diintroduksikan oleh para pengembang (Rumagit, 1997).

Perkembangan zaman yang semakin pesat juga diikuti oleh perkembangan teknologi, membuat banyak perusahaan baik berskala besar maupun kecil semakin giat mengembangkan rangkaian produk rumah kayu Minahasa yang dibangun dengan teknik modern tanpa menghilangkan unsur tradisional dari rumah kayu ini. CV Tumou Pratama merupakan salah satu UKM yang bergerak dalam usaha rumah kayu Woloan. Perusahaan yang dimiliki Bapak Stefanus T. Wetik, SH ini sah berdiri pada tahun 2014 dan berlokasi di Kelurahan Woloan 1 Kecamatan Tomohon Barat.

CV Tumou Pratama perlu diteliti lebih lanjut khususnya tentang analisis keuntungan usahanya, hal ini dikarenakan umur perusahaan yang masih tergolong muda. Menurut Soekartawi (2002) untuk mengetahui apakah usaha yang dilaksanakan mengalami keuntungan atau kerugian, maka diperlukan analisis $\mathrm{R} / \mathrm{C}$ yang merupakan perbandingan antara penerimaan dan biaya-biaya yang dikeluarkan selama proses produksi rumah kayu. Karena tujuan dari setiap usaha yang didirikan pada umumnya adalah untuk memperoleh keuntungan semaksimal mungkin.

\section{Rumusan Masalah}

Rumusan masalah dalam penelitian ini adalah berapa besar keuntungan usaha rumah kayu CV Tumou Pratama di Kelurahan Woloan 1 Kecamatan Tomohon Barat.

\section{Tujuan Penelitian}

Tujuan dari penelitian ini adalah untuk menganalisis keuntungan usaha rumah kayu $\mathrm{CV}$ Tumou Pratama di Kelurahan Woloan 1 Kecamatan Tomohon Barat. 


\section{Manfaat Penelitian}

1. Sebagai bahan informasi bagi CV Tumou Pratama, hasil penelitian ini diharapkan berguna untuk pengembangan usaha rumah kayu Minahasa.

2. Hasil penelitian ini diharapkan dapat digunakan oleh instansi terkait seperti Pemerintah, serta pihak-pihak yang berhubungan dengan pengambilan kebijakan.

3. Penelitian ini diharapkan dapat digunakan untuk menambah wawasan dan pengetahuan dalam berbagai temuan dan permasalahan yang belum terungkap di lapangan, serta digunakan dalam penerapan konsep dan teori-teori pada penelitian di bidang yang sejenis.

\section{METODE PENELITIAN}

\section{Lokasi dan Waktu Penelitian}

Penelitian ini dilaksanakan pada CV Tumou Pratama Kelurahan Woloan 1 Kecamatan Tomohon Barat sebagai usaha yang menghasilkan rumah kayu. Penelitian ini dilakukan selama 3 bulan mulai dari bulan September - November 2018.

\section{Jenis dan Sumber Data}

Data yang dipakai dalam penelitian ini adalah data primer dan data sekunder. Data primer merupakan data mentah yang diambil oleh peneliti dilapangan langsung dari sumbernya yaitu pemilik usaha rumah kayu CV Tumou Pratama di Kelurahan Woloan 1 Kecamatan Tomohon Barat. Data ini diperoleh dari wawancara secara langsung, sedangkan data sekunder diperoleh dari Badan Pusat Statistik, Internet dan sumber lain yang memiliki relevansi dalam penelitian ini.

\section{Teknik Pengumpulan Data}

Teknik pengumpulan data yang digunakan dalam penelitian ini adalah sebagai berikut :

1) Observasi

Mengadakan pengamatan langsung terhadap objek yang diteliti sehingga didapatkan gambaran yang jelas mengenai objek yang diteliti tersebut.

2) Wawancara

Pengumpulan data yang dilakukan dengan cara tanya jawab, tatap muka antara pewawancara dengan responden berdasarkan daftar pertanyaan (quisioner) yang telah dipersiapkan sebelumnya.
3) Pencatatan

Mencatat hasil wawancara pada daftar pertanyaan (quisioner) dan mencatat data sekunder dari instansi pemerintah atau lembaga yang terkait dengan penelitian ini.

\section{Konsep Pengukuran Variabel}

Variabel-variabel yang diukur serta digunakan dalam penelitian ini adalah :

1) Produksi (Unit)

Yaitu jumlah produksi rumah kayu berdasarkan tipe terdiri dari : Tipe Kecil (36 $\left.\mathrm{m}^{2}\right)$, Tipe Sedang $\left(70 \mathrm{~m}^{2}\right)$, Tipe Besar $\left(112 \mathrm{~m}^{2}\right)$ dan Tipe Ekstra $\left(198 \mathrm{~m}^{2}\right)$.

2) Harga (Rp)

Harga jual dari produk rumah kayu.

3) Biaya Produksi (Rp)

Yaitu besarnya biaya yang dikeluarkan dalam pembuatan rumah kayu dalam setiap kali produksi yang terdiri dari :

\section{a. Biaya Tetap (Fixed Cost)}

- Biaya Penyusutan Peralatan (Rp).

Yaitu nilai penyusutan selama 1 tahun dari alat-alat yang digunakan dalam proses produksi rumah kayu. Nilai penyusutan dihitung dengan menggunakan metode garis lurus atau straight line method

Biaya Penyusutan $=\frac{\text { Harga Pembelian-Nilai Ekonomis }}{\text { Umur Ekonomis }}$

- Lahan (Rp).

Pengukuran nilai lahan didasarkan kepada

- kemampuan lahan secara ekonomis.

- Bangunan (Rp).

Adalah konstruksi bangunan industri pembuatan rumah kayu terhadap umur ekonomis bangunan tersebut.

- Pajak Kendaraan (Rp) Yaitu nilai pajak sejak tahun keluaran

- kendaraan yang dibeli.

- Biaya Pemeliharaan Kendaraan Pengeluaran per tahun yang dikeluarkan untuk servis dan penggantian suku cadang kendaraan.

- Biaya Website (Rp) Pengeluaran per tahun yang dikeluarkan untuk memasarkan produk rumah kayu melalui website www.rumahkayu123.com

b. Biaya Variabel (Variable Cost) meliputi :

- Biaya Bahan Baku (Rp).

- Biaya Bahan Penolong (Rp).

- Biaya Tenaga Kerja (Rp).

- Biaya Listrik (Rp).

- Biaya Bahan Bakar (Rp). 
4) Penerimaan (Rp).

Yaitu perkalian antara produksi yang diperoleh dengan harga jual.

5) Keuntungan (Rp).

Yaitu nilai yang diperoleh dari hasil penjualan dikurangi dengan biaya yang dikeluarkan.

\section{Metode Analisis Data}

Data yang dikumpulkan dalam penelitian ini kemudian dianalisis dengan menggunakan:

\section{Analisis Keuntungan}

(profit analysis) yaitu dengan menghitung selisih antara penerimaan dengan biaya-biaya yang dikeluarkan.

Data yang dikumpulkan disajikan dalam bentuk variabel dan dianalisis secara deskriptif. Kemudian dilanjutkan dengan rumus Analisis Revenue Cost Ratio $(R / C)$. Menurut Soekartawi (2003) untuk mengukur benar keuntungan digunakan rumus sebagai berikut :

$$
\boldsymbol{\pi}=\mathbf{T R}-\mathbf{T C}
$$

Dimana :

$\pi \quad=$ Profit (Keuntungan)

TR = Total Revenue (Total Penerimaan)

$\mathrm{TC}=$ Total Cost (Total Biaya)

$$
\mathbf{T R}=\mathbf{Q} \cdot \mathbf{P q}
$$

Dimana :

TR = Total Penerimaan

$\mathrm{Q}=$ Jumlah Produksi yang dijual

$\mathrm{Pq} \quad=$ Harga Tiap Satuan Produk

$$
\mathbf{T C}=\mathbf{T F C}+\mathbf{T V C}
$$

Dimana :

$\mathrm{TC}($ Total Revenue $) \quad=$ Total Biaya

FC $($ Fixed Cost $)=$ Biaya Tetap

$\mathrm{VC}($ Variabel Cost $)=$ Biaya Variabel

Kemudian untuk mengetahui apakah usaha rumah kayu ini menguntungkan atau tidak dapat dihitung dengan rumus :

$$
\mathbf{a}=\mathbf{R} / \mathbf{C}
$$

Apabila :

$\mathrm{R} / \mathrm{C}=1$, Berarti usaha rumah kayu tidak untung atau tidak rugi

$\mathrm{R} / \mathrm{C}<1$, Berarti usaha rumah kayu ini rugi

$\mathrm{R} / \mathrm{C}>1$, Berarti usaha rumah kayu ini untung

Dimana :

$$
\begin{array}{ll}
\mathrm{a} & =\text { Revenue Cost Ratio } \\
\mathrm{R} & =\text { Revenue }(\text { Penerimaan }) \\
\mathrm{C} & =\text { Cost }(\text { Biaya })
\end{array}
$$

\section{PEMBAHASAN}

\section{Gambaran Umum Lokasi Penelitian}

Kota Tomohon terdiri dari 5 Kecamatan dengan 44 Kelurahan dan 299 Lingkungan, dipimpin oleh Walikota dan Wakil Walikota. Kelurahan Woloan Satu Kecamatan Tomohon Barat merupakan sentra produksi rumah kayu dengan sistem konstruksi bongkar pasang (knock-down) yang berada di Kota Tomohon Provinsi Sulawesi Utara. Jarak dari Kota Tomohon ke Kecamatan Tomohon Barat adalah 2,0 km dan jarak dari Ibukota Kecamatan ke Kelurahan Woloan Satu adalah 1,0 km sedangkan Luas Wilayah Kecamatan Tomohon Barat menurut Kelurahan dapat dilihat pada Tabel 1.

Tabel 1. Luas Wilayah Kecamatan Tomohon Barat menurut Kelurahan

\begin{tabular}{lcr}
\hline \multicolumn{1}{c}{ Kelurahan } & Luas $\left(\mathrm{km}^{2}\right)$ & Persentase $(\%)$ \\
\hline Woloan Satu & 1,01 & 2,89 \\
Woloan Dua & 6,76 & 19,31 \\
Woloan Tiga & 1,40 & 4,01 \\
Taratara Satu & 6,25 & 17,87 \\
Taratara Dua & 5,26 & 15,03 \\
Woloan Satu Utara & 1,51 & 4,31 \\
Tara Tara & 6,00 & 17,14 \\
Taratara Tiga & 6,80 & 19,43 \\
\hline Jumlah & 34,99 & 100 \\
\hline Sumber : Badan Pusat Statistik Kota Tomohon, 2018
\end{tabular}

\section{Sejarah Pendirian Usaha Rumah Kayu CV Tumou Pratama}

Tumou Pratama adalah perusahaan dagang yang bergerak di bidang produksi dan penjualan rumah kayu knock-down. Usaha ini telah berjalan sejak tahun 2008 sebagai usaha keluarga di Kelurahan Woloan, Kota Tomohon Sulawesi Utara. Melihat perkembangan usaha Tumou Pratama, maka pada hari Jumat, 8 Agustus 2014, didirikanlah Badan Usaha Persekutuan Komanditer "CV. Tumou Pratama" di hadapan ibu Ivonne Yuliet Pesik, SH., Notaris di Kota Tomohon dengan jabatan Direktur Utama Bapak Stefanus T. Wetik, SH

\section{Proses Produksi Rumah Kayu CV Tumou Pratama}

Gambar 1 menunjukkan bahwa proses produksi rumah kayu terdiri dari 4 tahapan, yaitu :

1) Tahap Pengumpulan Bahan Baku

Bahan baku untuk pembuatan rumah kayu di pesan dan di kirim langsung oleh pemasok kayu yang berasal dari Kabupaten Bolaang Mangondow Utara dan Bolaang Mangondow Selatan. 
2) Tahap Pengolahan

Dilakukan proses mekanisasi terhadap setiap bagian-bagian kayu berdasarkan ukuran yang telah ditetapkan menggunakan mesin.

3) Tahap Perakitan Rumah Kayu

Pada tahap ini, bagian-bagian dari rumah kayu yang sudah dibersihkan, dipotong dan dibor sesuai ukuran masing-masing kemudian dirakit dengan bahan penolong.

2) Pemasangan Rumah Kayu

Rumah kayu sudah berada di lokasi dari konsumen yang memesan rumah kayu untuk dipasang serta didirikan menjadi sebuah hunian yang diinginkan konsumen. Keseluruhan waktu yang dibutuhkan untuk memproduksi 1 (satu) unit rumah kayu untuk tipe kecil $\left(36 \mathrm{~m}^{2}\right)$ 12 hari, tipe sedang $\left(70 \mathrm{~m}^{2}\right) 24$ hari, tipe besar $\left(112 \mathrm{~m}^{2}\right) 48$ hari dan tipe ekstra $\left(198 \mathrm{~m}^{2}\right) 96$ hari.

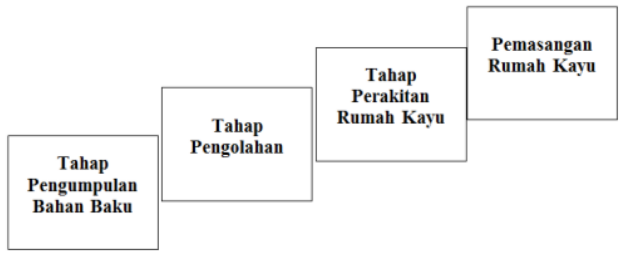

Gambar 1. Tahapan Produksi Rumah Kayu

\section{Produk dan Harga Rumah Kayu}

Kegiatan produksi yang dilakukan oleh CV Tumou Pratama adalah untuk menghasilkan rumah kayu yang dipesan/diiginkan konsumen dengan cara mengolah bahan baku kayu dan bahan penolong (input) menjadi rumah kayu (output). Rincian jumlah produk rumah kayu dapat dilihat pada Tabel 2.

Tabel 2. Produk Rumah Kayu CV Tumou Pratama Tahun 2017 sampai Tahun 2018

\begin{tabular}{llccc}
\hline No & Jenis Produk & 2017 & 2018 & Jumlah Unit \\
\hline 1 & Tipe Kecil $\left(36 \mathrm{~m}^{2}\right)$ & 2 & 4 & 6 \\
2 & Tipe Sedang $\left(70 \mathrm{~m}^{2}\right)$ & 3 & 2 & 5 \\
3 & Tipe Besar $\left(112 \mathrm{~m}^{2}\right)$ & 1 & 2 & 3 \\
4 & Tipe Ekstra $\left(198 \mathrm{~m}^{2}\right)$ & - & 1 & 1 \\
\hline & Total & 6 & 9 & 15 \\
\hline
\end{tabular}

Sumber : Data Primer, 2018

Tabel 2 menunjukkan bahwa total produk rumah kayu CV Tumou Pratama yang dipesan oleh konsumen pada tahun 2017 sampai tahun 2018 sebanyak 15 unit. Harga jual rumah kayu untuk tipe kecil $\left(36 \mathrm{~m}^{2}\right)$ sebesar Rp.72.000.000, tipe sedang $\left(70 \mathrm{~m}^{2}\right)$ sebesar Rp.140.000.000, tipe besar $\left(112 \mathrm{~m}^{2}\right)$ sebesar Rp.224.000.000 dan tipe ekstra $\left(198 \mathrm{~m}^{2}\right)$ sebesar Rp.396.000.000 sedangkan harga per meter untuk keseluruhan tipe rumah kayu sebesar Rp.2.000.000/ $\mathrm{m}^{2}$

\section{Biaya Produksi}

Biaya produksi adalah akumulasi dari semua biaya-biaya yang dibutuhkan selama proses pembuatan rumah kayu setiap kali produksi yang terdiri dari :

\section{A. Biaya Tetap (Fixed Cost)}

Komponen biaya tetap pada CV Tumou Pratama terdiri dari biaya penyusutan mesin, lahan, bangunan, pajak kendaraan, biaya pemeliharaan kendaraan dan biaya website. Kemudian masing-masing biaya tetap tersebut dibagi secara proporsional berdasarkan tipe rumah kayu, tipe kecil $\left(36 \mathrm{~m}^{2}\right) 10 \%$, tipe sedang $\left(70 \mathrm{~m}^{2}\right)$ $20 \%$, tipe besar $\left(112 \mathrm{~m}^{2}\right) 30 \%$ dan tipe ekstra (198 $\left.\mathrm{m}^{2}\right) 40 \%$.

1) Biaya Penyusutan Mesin

Nilai penyusutan selama mesin digunakan untuk proses produksi rumah kayu. Penyusutan masing-masing komponen dapat dilihat pada Tabel 3.

\begin{tabular}{llr}
\multicolumn{6}{l}{ Tabel 3. Nilai Penyusutan Mesin CV Tumou Pratama per Tahun } \\
\hline No & Komponen Biaya & Penyusutan per Tahun (Rp) \\
\hline 1 & Mesin Planer & 2.000 .000 \\
2 & Mesin Spindle & 1.500 .000 \\
3 & Mesin Iris & 1.800 .000 \\
4 & Mesin Iris Rakitan & 1.800 .000 \\
5 & Mesin Serut Makita tipe & 2.025 .000 \\
6 & Mesin Serut Ryobi tipe & 587.500 \\
7 & Mesin Bor & 221.250 \\
8 & Mesin Pencetak Profil & 1.040 .000 \\
9 & Mesin Asah Planer & 540.000 \\
10 & Mesin Presisi & 1.250 .000 \\
11 & Mesin Circle kecil & 62.500 \\
\hline & Total & 12.826 .250 \\
\hline
\end{tabular}

Tabel 3 menunjukkan total nilai penyusutan mesin CV Tumou Pratama dalam setahun yaitu sebesar Rp.12.826.250. Niilai penyusutan mesin yang dihitung berdasarkan metode garis lurus (straight line method) sesuai dengan umur ekonomisnya.

CV Tumou Pratama tidak memiliki alat bukan mesin seperti ; gergaji, palu, pahat, mistar siku dan lain-lain. semua alat bukan mesin yang digunakan dalam proses produksi rumah kayu dibawah oleh masing-masing tukang/pekerja rumah kayu.

2) Lahan

CV Tumou Pratama mengeluarkan biaya sebesar Rp.5.000.000/tahun untuk menyewa tanah seluas $420 \mathrm{~m}^{2}$ sebagai lokasi proses produksi. 
3) Bangunan

CV Tumou Pratama mengeluarkan biaya sebesar Rp.15.000.000 untuk mendirikan bangunan induk seluas $246 \mathrm{~m}^{2}$ sebagai tempat proses produksi.

4) Pajak Kendaraan

Kendaraan yang dibeli CV Tumou Pratama pada tahun 2015 memiliki nilai pajak sebesar Rp.2.220.000/tahun.

5) Biaya Pemeliharaan Kendaraan

Biaya pemeliharaan yang dikeluarkan termasuk servis dan penggantian suku cadang kendaraan yaitu sebesar Rp.2.500.000/tahun.

6) Biaya Website

CV Tumou Pratama mengeluarkan biaya sebesar Rp.500.000/tahun untuk biaya websit ewww.rumahkayu123.c om.

Rincian biaya tetap untuk 4 tipe rumah kayu CV Tumou Pratama dalam satu kali produksi dapat dilihat pada Tabel 4 .

\begin{tabular}{|c|c|c|c|c|}
\hline \multirow{2}{*}{$\begin{array}{c}\text { Komponen } \\
\text { Biaya }\end{array}$} & \multicolumn{4}{|c|}{ Jumlah (Rp) } \\
\hline & $\begin{array}{l}\text { Tipe Kecil } \\
\left(36 \mathrm{~m}^{2}\right)\end{array}$ & $\begin{array}{l}\text { Tipe Sedang } \\
\quad\left(70 \mathrm{~m}^{2}\right)\end{array}$ & $\begin{array}{l}\text { Tipe Besar } \\
\left(112 \mathrm{~m}^{2}\right)\end{array}$ & $\begin{array}{l}\text { Tipe Ekstra } \\
\left(198 \mathrm{~m}^{2}\right)\end{array}$ \\
\hline $\begin{array}{l}\text { Penyusutan } \\
\text { Peralatan }\end{array}$ & 1.282 .625 & 2.565 .250 & 3.847 .875 & 5.130 .500 \\
\hline Lahan & 500.000 & 1.000 .000 & 1.500 .000 & 2.000 .000 \\
\hline Bangunan & 1.500 .000 & 3.000 .000 & 4.500 .000 & 6.000 .000 \\
\hline $\begin{array}{l}\text { Pajak } \\
\text { Kendaraan }\end{array}$ & 222.000 & 444.000 & 666.000 & 888.000 \\
\hline $\begin{array}{l}\text { Pemeliharaan } \\
\text { Kendaraan }\end{array}$ & 250.000 & 500.000 & 750.000 & 1.000 .000 \\
\hline $\begin{array}{l}\text { Biaya } \\
\text { Website }\end{array}$ & 50.000 & 100.000 & 150.000 & 200.000 \\
\hline $\begin{array}{l}\text { Total Biaya } \\
\text { Tetap }\end{array}$ & 3.804 .625 & 7.609 .250 & 11.413 .875 & 15.218 .500 \\
\hline
\end{tabular}

Tabel 4 menunjukkan biaya tetap yang paling tinggi ada pada tipe ekstra $\left(198 \mathrm{~m}^{2}\right)$ dengan biaya sebesar Rp.15.218.500 karena merupakan tipe rumah kayu yang paling luas ukurannya dibandingkan tipe yang lain. Sedangkan biaya tetap yang paling rendah ada pada tipe kecil (36 $\mathrm{m}^{2}$ ) dengan biaya sebesar Rp.3.804.625 dari total biaya tetap berdasarkan tipe rumah kayu.

\section{B. Biaya Variabel (Variable Cost)}

Komponen biaya variabel CV Tumou Pratama terdiri dari biaya bahan baku, biaya bahan penolong, biaya tenaga kerja, biaya listrik, biaya bahan bakar.

1) Biaya Bahan Baku

Produk rumah kayu CV Tumou Pratama

akan tercipta karena adanya persediaan

bahan baku. Ketersediaan bahan baku kayumerupakan salah satu faktor utama kegiatan produksi rumah kayu bisa berjalan dengan baik. Pembuatan rumah kayu membutuhkan bahan baku yaitu kayu besi dan kayu meranti merah yang dipesan langsung dari pemasok kayu Bolaang Mangondow Utara dan Bolaang Mangondow Selatan.

2) Biaya Bahan Penolong

Bahan penolong merupakan faktor yang cukup penting agar kegiatan produksi rumah kayu juga bisa berjalan dengan baik. Pembuatan rumah kayu membutuhkan bahan penolong yaitu paku, baut, engsel pintu, engsel jendela, grendel jendela, kaca jendela, hak angin, tarikan, kunci pintu, cat clear, kuas, lem fox kecil, seng gelombang koala dan paku seng. Bahan penolong ini diperoleh dengan cara memesan/membeli langsung di toko bangunan terdekat.

Rincian biaya penggunaan bahan baku dan bahan penolong berdasarkan tipe rumah kayu dalam satu kali produksi dapat dilihat pada Tabel 5, 6, 7 dan 8 .

Tabel 5. Biaya penggunaan Bahan Baku dan Bahan Penolong Tipe Kecil $\left(36 \mathrm{~m}^{2}\right)$

\begin{tabular}{|c|c|c|c|c|}
\hline No & Jenis Bahan & Satuan & $\begin{array}{c}\text { Harga } \\
\text { Satuan (Rp) }\end{array}$ & Jumlah (Rp) \\
\hline \multirow[t]{3}{*}{1} & Bahan Baku : & & & \\
\hline & Kayu Besi & $2 \mathrm{~m}^{3}$ & 3. 400.000 & 6.800 .000 \\
\hline & Kayu Meranti Merah & $2,5 \mathrm{~m}^{3}$ & 3.000 .000 & 7.500 .000 \\
\hline \multirow[t]{25}{*}{2} & Bahan Penolong : & & & \\
\hline & Paku : & & & \\
\hline & 1 inch & $1 \mathrm{~kg}$ & 22.000 & 22.000 \\
\hline & 1,5 inch & $1,5 \mathrm{~kg}$ & 22.000 & 33.000 \\
\hline & 2 inch & $1 \mathrm{~kg}$ & 22.000 & 22.000 \\
\hline & 2,5 inch & $3 \mathrm{~kg}$ & 18.000 & 54.000 \\
\hline & Inch & $2 \mathrm{~kg}$ & 18.000 & 36.000 \\
\hline & Baut & & & \\
\hline & $3 / 8 \times 4$ inch & 6 buah & 4.300 & 25.800 \\
\hline & $3 / 8 \times 8$ inch & 8 buah & 4.500 & 36.000 \\
\hline & Engsel Pintu & 4 pasang & 27.000 & 108.000 \\
\hline & Engsel Jendela & 8 pasang & 21.000 & 168.000 \\
\hline & Grendel Jendela & 8 pasang & 10.000 & 80.000 \\
\hline & Kaca Jendela & 8 lembar & 69.000 & 552.000 \\
\hline & Hak Angin & 8 buah & 10.000 & 80.000 \\
\hline & Tarikan & 8 buah & 10.000 & 80.000 \\
\hline & Kunci Pintu & 4 paket & 100.000 & 400.000 \\
\hline & Cat Clear & 10 kaleng & 72.000 & 720.000 \\
\hline & Kuas : & & & \\
\hline & 2 inchinch & 1 buah & 4.000 & 4.000 \\
\hline & 3 inch & 3 buah & 6.000 & 18.000 \\
\hline & Lem Fox Kecil & 2 buah & 9.000 & 18.000 \\
\hline & 4 Seng Gelombang & 1 botol & 10.000 & 10.000 \\
\hline & Koala & 75 & 60.000 & 4.500 .000 \\
\hline & 3 Paku Seng & $\begin{array}{r}\text { lembar } \\
1,5 \mathrm{~kg}\end{array}$ & 18.000 & 27.000 \\
\hline Tota & & & & 21.293 .800 \\
\hline
\end{tabular}

Tabel 5 menunjukkan total biaya penggunaan bahan baku dan bahan penolong rumah kayu tipe kecil $\left(36 \mathrm{~m}^{2}\right)$ adalah sebesar Rp.21.293.800. Sedangkan biaya penggunaan bahan baku dan bahan penolong per $\mathrm{m}^{2}$ rumah kayu tipe kecil sebesar Rp.591.494. 


\begin{tabular}{|c|c|c|c|c|}
\hline No & Jenis Bahan & Satuan & Harga Satuan $(\mathrm{Rp})$ & Jumlah (Rp) \\
\hline \multirow{3}{*}{1} & Bahan Baku : & & & \\
\hline & - Kayu Besi & $4 \mathrm{~m}^{3}$ & 3.400 .000 & 13.600 .000 \\
\hline & - Kayu Meranti Merah & $5 \mathrm{~m}^{3}$ & 3.000 .000 & 15.000 .000 \\
\hline \multirow[t]{25}{*}{2} & Bahan Penolong : & & & \\
\hline & -Paku : & & & \\
\hline & $\begin{array}{l}1 \text { inch } \\
1.5 \text { inch }\end{array}$ & $\begin{array}{l}1,3 \mathrm{~kg} \\
2 \mathrm{~kg}\end{array}$ & 22.000 & $\begin{array}{l}33.000 \\
44.000\end{array}$ \\
\hline & $\begin{array}{l}1,5 \text { inch } \\
2 \text { inch }\end{array}$ & $2 \mathrm{~kg}$ & 22.000 & 44.000 \\
\hline & 2,5 inch & $5 \mathrm{~kg}$ & 18.000 & 90.000 \\
\hline & 3 inch & $3 \mathrm{~kg}$ & 18.000 & 54.000 \\
\hline & -Baut : & & & \\
\hline & $3 / 8 \times 4$ inch & $10 \mathrm{buah}$ & 4.300 & 43.000 \\
\hline & $3 / 8 \times 8$ inch & 14 buah & 4.500 & 63.000 \\
\hline & - Engsel Pintu & 5 pasang & 27.000 & 135.000 \\
\hline & - Engsel Jendela & 12 pasang & 21.000 & 252.000 \\
\hline & - Grendel Jendela & 12 pasang & 10.000 & 120.000 \\
\hline & - Kaca Jendela & 12 lembar & 69.000 & 828.000 \\
\hline & - Hak Angin & 12 buah & 10.000 & 120.000 \\
\hline & - Tarikan & 12 buah & 10.000 & 120.000 \\
\hline & - Kunci Pintu & 5 paket & 100.000 & 500.000 \\
\hline & - Cat Clear & 14 kaleng & 72.000 & 1.008 .000 \\
\hline & - Kuas : & & & \\
\hline & 2 inch & 1 buah & 4.000 & 4.000 \\
\hline & 3 inch & 2 buah & 6.000 & 12.000 \\
\hline & 4 inch & 3 buah & 9.000 & 27.000 \\
\hline & - Lem Fox kecil & 2 botol & 10.000 & 20.000 \\
\hline & - Seng Gelombang Koala & 110 lembar & 60.000 & 6.600 .000 \\
\hline & -5 Paku Seng & $2,5 \mathrm{~kg}$ & 18.000 & 45.000 \\
\hline & Total & & & 38.762 .000 \\
\hline
\end{tabular}

Tabel 6 menunjukkan total biaya penggunaan bahan baku dan bahan penolong rumah kayu tipe sedang $\left(70 \mathrm{~m}^{2}\right)$ adalah sebesar Rp.38.762.000. Sedangkan biaya penggunaan bahan baku dan bahan penolong per $\mathrm{m}^{2}$ rumah kayu tipe sedang sebesar Rp.553.742.

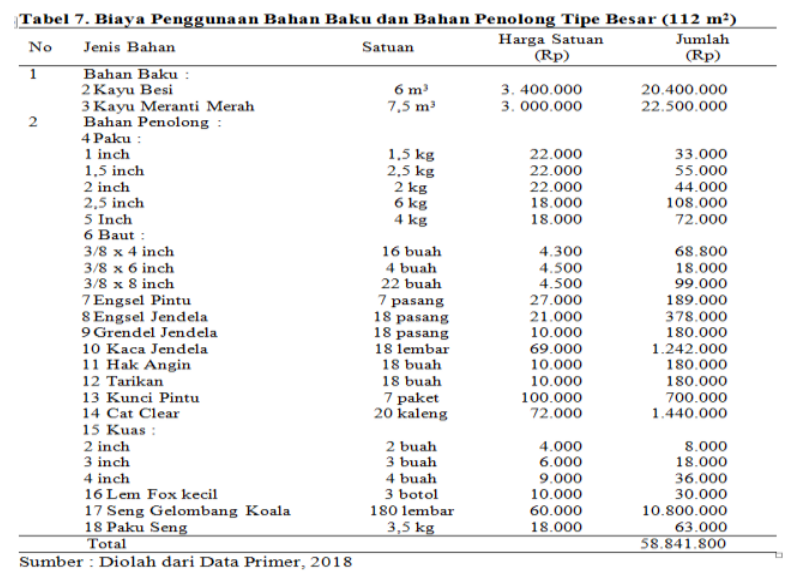

Tabel 7 menunjukkan total biaya penggunaan bahan baku dan bahan penolong rumah kayu tipe besar $\left(112 \mathrm{~m}^{2}\right)$ adalah sebesar Rp.58.841.800. Sedangkan biaya penggunaan bahan baku dan bahan penolong per $\mathrm{m}^{2}$ rumah kayu tipe besar sebesar Rp.525.37.

Tabel 8 menunjukkan total biaya penggunaan bahan baku dan bahan penolong rumah kayu tipe besar $\left(198 \mathrm{~m}^{2}\right)$ adalah sebesar Rp.86.743.800. Sedangkan biaya penggunaan bahan baku dan bahan penolong per $\mathrm{m}^{2}$ rumah kayu tipe ekstra sebesar Rp.438.100.

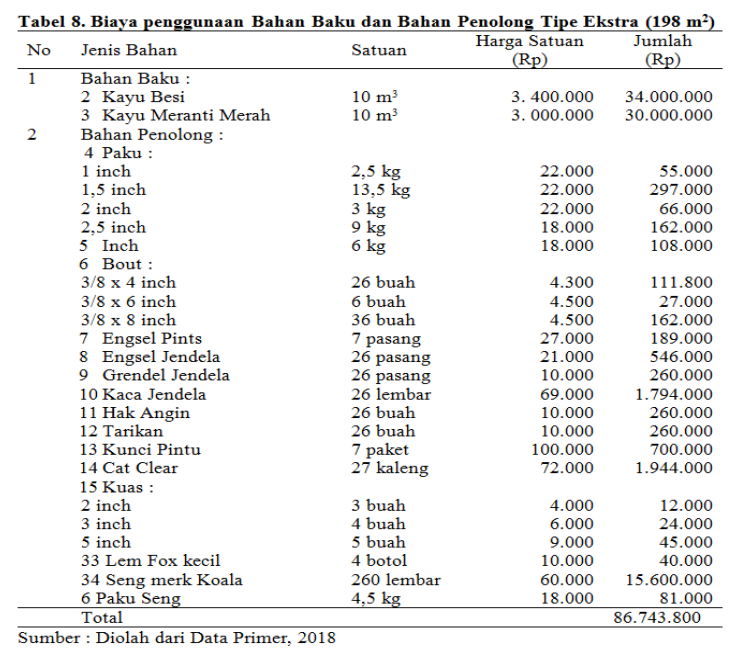

3) Biaya Tenaga Kerja

CV Tumou Pratama memiliki 27 orang tenaga kerja tidak tetap, terdiri 1 orang kepala tukang dan 26 orang tukang yang membuat 4 tipe rumah kayu. Rincian alokasi biaya tenaga kerja berdasarkan tipe rumah kayu dapat dilihat pada Tabel 9.

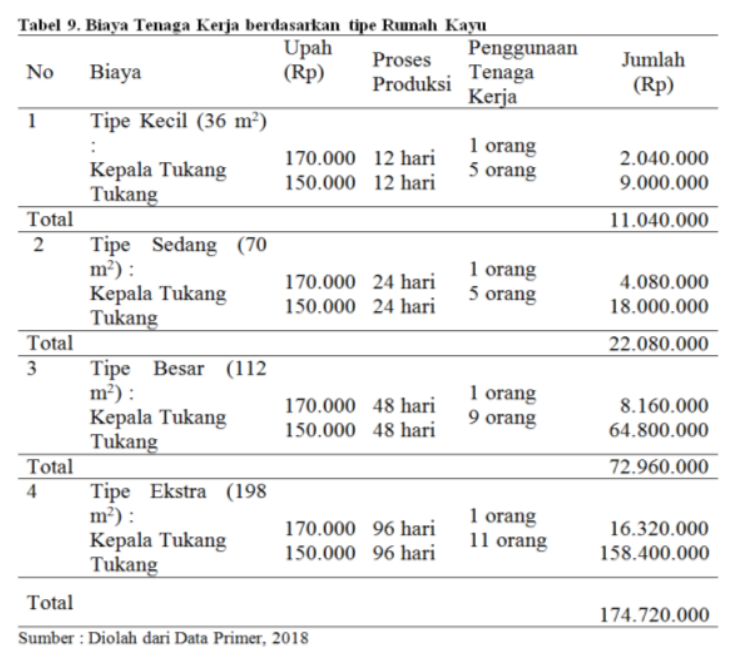

Tabel 9 menunjukkan biaya tenaga kerja yang paling tinggi ada pada tipe ekstra (198 $\mathrm{m}^{2}$ ) dengan biaya sebesar Rp.174.720.000 karena merupakan tipe rumah kayu yang paling lama proses produksinya yaitu selama 96 hari kerja dibandingkan dengan tiga tipe lain.

4) Biaya Listrik

CV Tumou Pratama mengeluarkan biaya sebesar Rp.500.000/bulan untuk penggunaan listrik dalam proses produksi rumah kayu. 
5) Biaya Bahan Bakar

Biaya bahan bakar yang dikeluarkan untuk operasional kendaraan yaitu sebesar Rp.200.000/minggu.

Besar penggunaan biaya listrik dan biaya bahan bakar tergantung dari waktu operasional mobil selama pengerjaan rumah kayu. Rincian biaya variable untuk 4 tipe rumah kayu $\mathrm{CV}$ Tumou Pratama dalam satu kali produksi dapat dilihat pada Tabel 10.

\begin{tabular}{|c|c|c|c|c|}
\hline \multirow[b]{2}{*}{ Komponen Biaya } & \multicolumn{4}{|l|}{ Jumlah (Rp) } \\
\hline & $\begin{array}{l}\text { Tipe Kecil } \\
\left(36 \mathrm{~m}^{2}\right)\end{array}$ & $\begin{array}{l}\text { Tipe Sedang } \\
\left(70 \mathrm{~m}^{2}\right)\end{array}$ & $\begin{array}{l}\text { Tipe Bear } \\
\left(112 \mathrm{~m}^{2}\right)\end{array}$ & $\begin{array}{l}\text { Tipe Ekstra } \\
\left(198 \mathrm{~m}^{2}\right)\end{array}$ \\
\hline $\begin{array}{l}\text { Bayar Bahan Baku } \\
\text { dan Bahan Penolong }\end{array}$ & 21.293 .800 & 38.762 .000 & 58.841 .800 & 86.743 .800 \\
\hline Biaya Tenaga Kerja & 11.040 .000 & 22.080 .000 & 72.960 .000 & 174.720 .000 \\
\hline Biaya Listrik & R2250.000 & 500.000 & 1.000 .000 & 2.000 .000 \\
\hline Baima Bahan Bakar & 400.000 & 800.000 & 1.600 .000 & 3.200 .000 \\
\hline Total & 32.983 .800 & 62.142 .000 & 134.401 .800 & 266.663 .800 \\
\hline
\end{tabular}

Tabel 10 menunjukkan biaya variabel berdasarkan tipe rumah kayu yang paling tinggi ada pada tipe ekstra $\left(198 \mathrm{~m}^{2}\right)$ dengan biaya sebesar Rp.266.663.800 karena merupakan tipe rumah kayu yang paling luas serta jangka waktu yang dibutuhkan untuk produksi rumah kayu tipe ekstra lebih lama dibandingkan tipe yang lain. Sedangkan biaya variabel yang paling rendah ada pada tipe kecil $\left(36 \mathrm{~m}^{2}\right)$ dengan biaya sebesar Rp. 32.983 .800 dari total biaya variabel berdasarkan tipe rumah kayu.

\section{Biaya Total (Total Cost)}

Biaya total yang digunakan untuk memproduksi rumah kayu berdasarkan tipe dalam satu kali produksi dan biaya total CV Tumou Pratama yang digunakan untuk memproduksi rumah kayu periode tahun 2017 sampai tahun 2018 dapat dilihat pada Tabel 11 dan 12 .

\begin{tabular}{lcccc}
\multicolumn{6}{l}{ Tabel 11. Biaya Total berdasarkan tipe Rumah Kayu } \\
$\begin{array}{l}\text { Komponen } \\
\text { Biaya }\end{array}$ & $\begin{array}{c}\text { Tipe Kecil } \\
\left(36 \mathrm{~m}^{2}\right) \\
(\mathrm{Rp})\end{array}$ & $\begin{array}{c}\text { Tipe } \\
\text { Sedang } \\
\left(70 \mathrm{~m}^{2}\right) \\
(\mathrm{Rp})\end{array}$ & $\begin{array}{c}\text { Tipe Besar } \\
\left(112 \mathrm{~m}^{2}\right) \\
(\mathrm{Rp})\end{array}$ & $\begin{array}{c}\text { Tipe Ekstra } \\
\left(198 \mathrm{~m}^{2}\right) \\
(\mathrm{Rp})\end{array}$ \\
\hline $\begin{array}{l}\text { Biaya } \\
\text { Tetap }\end{array}$ & 3.804 .625 & 7.609 .250 & 11.413 .875 & 15.218 .500 \\
Biaya & 32.983 .800 & 62.142 .000 & 134.401 .800 & 266.663 .800 \\
Variabel & & & & \\
\hline Total & 36.788 .425 & 69.751 .250 & 145.815 .675 & 281.882 .300 \\
\hline Sumber: Diolah dari Data Primer, 2018
\end{tabular}

Tabel 11 menunjukkan biaya total berdasarkan tipe rumah kayu yang paling tinggi ada pada tipe ekstra $\left(198 \mathrm{~m}^{2}\right)$ dengan biaya sebesar Rp.281.882.300 dikarenakan luas dan waktu proses produksi dari rumah kayu tipe ekstra lebih luas dan lebih lama dibandingkan tipe yang lain. Dalam perhitungan ini, semakin luas dan semakin lama waktu proses produksi dari rumah kayu yang dibutuhkan, maka semakin tinggi pula biaya bahan baku, biaya bahan penolong, biaya tenaga kerja, biaya listrik dan biaya bahan bakar yang dikeluarkan. Sedangkan biaya total yang paling rendah ada pada tipe kecil $\left(36 \mathrm{~m}^{2}\right)$ dengan biaya sebesar Rp.36.788.425. Tinggi rendahnya biaya variabel yang dikeluarkan mempengaruhi biaya total.

\begin{tabular}{|c|c|c|c|c|c|}
\hline \multirow{2}{*}{ Jenis Produk } & \multicolumn{2}{|c|}{$\begin{array}{c}\text { Jumlah } \\
\text { (Unit) }\end{array}$} & \multirow{2}{*}{$\begin{array}{c}\text { Biaya Total } \\
\text { (Rp/Unit) }\end{array}$} & \multicolumn{2}{|c|}{ Biaya Total (Rp) } \\
\hline & 2017 & 2018 & & 2017 & 2018 \\
\hline Tipe Kecil $\left(36 \mathrm{~m}^{2}\right)$ & 2 & 4 & 36.788 .425 & 73.576 .850 & 147.153 .700 \\
\hline Tipe Sedang $\left(70 \mathrm{~m}^{2}\right)$ & 3 & 2 & 69.751 .250 & 209.253 .750 & 139.502 .500 \\
\hline Tipe Besar $\left(112 \mathrm{~m}^{2}\right)$ & 1 & 2 & 145.815 .675 & 145.815 .675 & 291.631 .350 \\
\hline Tipe Ekstra $\left(198 \mathrm{~m}^{2}\right)$ & - & 1 & 281.882 .300 & - & 281.882 .300 \\
\hline Total & 6 & 9 & & 428.646 .275 & 860.169 .850 \\
\hline
\end{tabular}

Sumber : Diolah dari Data Primer, 2018

Tabel 12 menunjukkan biaya total rumah kayu yang merupakan hasil perkalian dari jumlah unit rumah kayu yang diproduksi dengan biaya total berdasarkan tipe rumah kayu dalam satu kali produksi. Yang paling tinggi ada pada tahun 2018 dengan biaya sebesar Rp.860.169.850 dikarenakan adanya peningkatan unit rumah kayu yang diproduksi sejumlah 9 unit, lebih banyak dari periode tahun 2017 sejumlah 6 unit rumah kayu dengan biaya total sebesar Rp.428.646.275.

\section{Penerimaan (Revenue)}

Penerimaan merupakan perkalian antara jumlah produksi dengan harga jual yang telah disepakati bersama oleh produsen dan konsumen. Rincian penerimaan rumah kayu CV Tumou Pratama periode tahun 2017 sampai tahun 2018 dapat dilihat pada Tabel 13.

Tabel 13. Penerimaan Rumah Kayu CV Tumou Pratama Periode Tahun 2017 sampai Tahun 2018

\begin{tabular}{lllllll}
\hline \multirow{2}{*}{ Jenis Produk } & \multicolumn{3}{c}{$\begin{array}{c}\text { Jumlah } \\
\text { (Unit) }\end{array}$} & \multirow{2}{*}{$\begin{array}{c}\text { Harga } \\
\text { (Rp/Unit) }\end{array}$} & \multicolumn{3}{c}{ Penerimaan $(\mathrm{Rp})$} \\
\cline { 2 - 3 } \cline { 5 - 6 } & 2017 & 2018 & & 2017 & 2018 \\
\hline Tipe Kecil $\left(36 \mathrm{~m}^{2}\right)$ & 2 & 4 & 72.000 .000 & 144.000 .000 & 288.000 .000 \\
Tipe Sedang $\left(70 \mathrm{~m}^{2}\right)$ & 3 & 2 & 140.000 .000 & 420.000 .000 & 280.000 .000 \\
Tipe Besar $\left(112 \mathrm{~m}^{2}\right)$ & 1 & 2 & 224.000 .000 & 224.000 .000 & 448.000 .000 \\
Tipe Ekstra $\left(198 \mathrm{~m}^{2}\right)$ & - & 1 & 396.000 .000 & - & 396.000 .000 \\
\hline Total & 6 & 9 & & 788.000 .000 & 1.412 .000 .000 \\
\hline Sumber : Diolah dari Data Primer, 2018 & & &
\end{tabular}

Tabel 13 menunjukkan penerimaan rumah kayu yang merupakan hasil perkalian dari jumlah unit rumah kayu yang diproduksi dengan harga jual per unit berdasarkan tipe rumah kayu. Yang paling tinggi ada pada tahun 2018 dengan penerimaan sebesar Rp.1.412.000.000 dikarenakan adanya 
peningkatan unit rumah kayu yang dijual sejumlah 9 unit, lebih banyak dari periode tahun 2017 sejumlah 6 unit rumah kayu dengan penerimaan sebesar Rp.788.000.000.

\section{Keuntungan (Profit)}

Yaitu pengurangan antara hasil penjualan produk rumah kayu dengan semua biaya yang dikeluarkan selama proses produksi rumah kayu. Rincian keuntungan rumah kayu periode tahun 2017 sampai tahun 2018 dan keuntungan per $\mathrm{m}^{2}$ masingmasing tipe rumah kayu CV Tumou Pratama dapat dilihat pada Tabel 14 dan 15 .

\begin{tabular}{lrrr}
\multicolumn{4}{c}{ Tabel 14. Keuntungan Rumah Kayu CV Tumou Pratama Periode Tahun 2017 sampai Tahun 2018 } \\
\multicolumn{1}{c}{ Aspek } & 2017 & 2018 & Jumlah \\
\hline Tipe Kecil $\left(36 \mathrm{~m}^{2}\right)$ & 144.000 .000 & 288.000 .000 & 432.000 .000 \\
Tipe Sedang $\left(70 \mathrm{~m}^{2}\right)$ & 420.000 .000 & 280.000 .000 & 700.000 .000 \\
Tipe Besar $\left(112 \mathrm{~m}^{2}\right)$ & 224.000 .000 & 448.000 .000 & 672.000 .000 \\
TipeEkstra $\left(198 \mathrm{~m}^{2}\right)$ & - & 396.000 .000 & 396.000 .000 \\
\hline Penerimaan: & 788.000 .000 & 1.412 .000 .000 & 2.200 .000 .000 \\
\hline Tipe Kecil $\left(36 \mathrm{~m}^{2}\right)$ & 73.576 .850 & 147.153 .700 & 220.730 .550 \\
Tipe Sedang $\left(70 \mathrm{~m}^{2}\right)$ & 209.253 .750 & 139.502 .500 & 348.756 .250 \\
Tipe Besar $\left(112 \mathrm{~m}^{2}\right)$ & 145.815 .675 & 291.631 .350 & 437.447 .025 \\
TipeEkstra $\left(198 \mathrm{~m}^{2}\right)$ & - & 281.882 .300 & 281.882 .300 \\
\hline Biaya: & 428.646 .275 & 860.169 .850 & 1.288 .816 .125 \\
\hline Tipe Kecil $\left(36 \mathrm{~m}^{2}\right)$ & 70.423 .150 & 140.846 .300 & 211.269 .450 \\
Tipe Sedang $\left(70 \mathrm{~m}^{2}\right)$ & 210.746 .250 & 140.497 .500 & 351.243 .750 \\
Tipe Besar $\left(112 \mathrm{~m}^{2}\right)$ & 78.184 .325 & 156.368 .650 & 234.552 .975 \\
Tipe Ekstra $\left(198 \mathrm{~m}^{2}\right)$ & & 114.117 .700 & 114.117 .700 \\
Keuntungan & 359.353 .725 & 551.830 .150 & 911.183 .875 \\
\hline Sumber : Diolah dari Data Primer, 2018 & &
\end{tabular}

Tabel 14 menunjukkan keuntungan rumah kayu selama periode tahun 2017 sampai tahun 2018 sebesar Rp.911.183.875 dari hasil penjualan 6 dan 9 unit rumah kayu pada berbagai tipe. Secara rata-rata usaha rumah kayu memperoleh keuntungan per tahun masing-masing sebesar Rp.359.353.725 dan Rp.551.830.150 atau Rp.29.946.144 dan Rp.45.985.846 per bulan. Rumah kayu tipe sedang $\left(70 \mathrm{~m}^{2}\right)$ memperoleh keuntungan yang paling tinggi dibandingkan tipe yang lain, hal ini berkaitan erat dengan jumlah penerimaan dari hasil penjualan rumah kayu tipe sedang paling tinggi serta merupakan tipe yang paling banyak diminati/dipesan oleh konsumen setelah rumah kayu tipe kecil. Walaupun tipe kecil lebih banyak dalam hal jumlah unit yang diproduksi, namun penerimaan yang diperoleh dari satu unit rumah kayu tipe kecil lebih rendah dibandingkan tipe sedang.

Tabel 15. Keuntungan per $\mathrm{m}^{2}$ masing-masing Tipe Rumah Kayu CV Tumou Pratama

\begin{tabular}{lllll}
\hline Unit & $\begin{array}{l}\text { Penerimaan } \\
\text { (profit) }\end{array}$ & $\begin{array}{l}\text { Biaya } \\
(\text { cost })\end{array}$ & $\begin{array}{l}\text { Keuntungan } \\
(\mathrm{Rp} / \text { Unit })\end{array}$ & $\begin{array}{l}\text { Keuntungan } \\
\left(\mathrm{Rp} / \mathrm{m}^{2}\right)\end{array}$ \\
\hline Tipe Kecil $\left(36 \mathrm{~m}^{2}\right)$ & 72.000 .000 & 36.788 .425 & 35.211 .575 & 978.099 \\
Tipe Sedang $\left(70 \mathrm{~m}^{2}\right)$ & 140.000 .000 & 69.751 .250 & 70.248 .750 & 1.003 .554 \\
Tipe Besar $\left(112 \mathrm{~m}^{2}\right)$ & 224.000 .000 & 145.815 .675 & 78.184 .325 & 698.074 \\
Tipe Ekstra $\left(198 \mathrm{~m}^{2}\right)$ & 396.000 .000 & 281.882 .300 & 114.117 .700 & 576.352 \\
\hline
\end{tabular}

Sumber : Diolah dari Data Primer, 2018
Tabel 15 menunjukkan keuntungan per $\mathrm{m}^{2}$ masing-masing tipe rumah kayu yang paling tinggi ada pada tipe sedang $\left(70 \mathrm{~m}^{2}\right)$ sebesar Rp.1.003.554 kemudian diikuti rumah kayu tipe kecil $\left(36 \mathrm{~m}^{2}\right)$ sebesar Rp.978.099, tipe besar $\left(112 \mathrm{~m}^{2}\right)$ sebesar Rp.698.074 dan tipe ekstra $\left(198 \mathrm{~m}^{2}\right)$ sebesar Rp.576.352. Hal ini dikarenakan penggunaan biaya bahan baku dan bahan penolong serta waktu pengerjaan rumah kayu tipe sedang lebih efisien dibandingkan tipe yang lain.

\section{Analisis Revenue Cost Ratio}

Tingkat keuntungan ekonomi usaha rumah kayu CV Tumou Pratama dapat diketahui dengan menggunakan Analisis Revenue Cost Ratio (R/C ratio) adalah perbandingan antara penerimaan dan biaya, ratio yang menjadi parameternya adalah nilai $\mathrm{R} / \mathrm{C}=1$ berarti usaha tidak untung atau tidak rugi, nilai $\mathrm{R} / \mathrm{C}<$ 1 berarti usaha rugi, nilai $\mathrm{R} / \mathrm{C}>1$ berarti usaha untung, dapat dilihat pada Tabel 16.

\begin{tabular}{llll}
\multicolumn{4}{l}{ Tabel 16. Revenue Cost Ratio Usaha Rumah Kayu CV Tumou Pratama } \\
\hline Keterangan & $\begin{array}{l}\text { Penerimaan } \\
\text { (Revenue) }\end{array}$ & $\begin{array}{l}\text { Biaya } \\
\text { (Cost) }\end{array}$ & Nilai R/C \\
\hline Tipe Kecil $\left(36 \mathrm{~m}^{2}\right)$ & 432.000 .000 & 220.730 .550 & 1,96 \\
Tipe Sedang $\left(70 \mathrm{~m}^{2}\right)$ & 700.000 .000 & 348.756 .250 & 2,01 \\
Tipe Besar $\left(112 \mathrm{~m}^{2}\right)$ & 672.000 .000 & 437.447 .025 & 1,54 \\
Tipe Ekstra $\left(198 \mathrm{~m}^{2}\right)$ & 396.000 .000 & 281.882 .300 & 1,41 \\
\hline
\end{tabular}

Sumber : Diolah dari Data Primer, 2018

Tabel 16 menunjukkan rumah kayu tipe sedang $\left(70 \mathrm{~m}^{2}\right)$ memperoleh nilai $\mathrm{R} / \mathrm{C}$ paling tinggi yaitu sebesar 2,01 kemudian diikuti nilai R/C tipe kecil $\left(36 \mathrm{~m}^{2)}\right)$ sebesar 1,96 , tipe besar $\left(112 \mathrm{~m}^{2}\right)$ sebesar 1,54 dan tipe ekstra $\left(198 \mathrm{~m}^{2}\right)$ sebesar 1,41 , maka dapat dinilai berdasarkan kriteria dari masingmasing tipe rumah kayu bahwa usaha ini menguntungkan.

\section{KESIMPULAN DAN SARAN}

\section{Kesimpulan}

Usaha rumah kayu CV Tumou Pratama di Kelurahan Woloan 1 Kecamatan Tomohon Barat selama periode tahun 2017 sampai tahun 2018 menguntungkan, baik secara total maupun berdasarkan tipe serta ukuran $\left(\mathrm{m}^{2}\right)$. Total keuntungan usaha rumah kayu sebesar 
Rp.911.183.875 dan Rumah Kayu Tipe Sedang $\left(70 \mathrm{~m}^{2}\right)$ merupakan tipe yang memberikan keuntungan per $\mathrm{m}^{2}$ paling tinggi yaitu sebesar Rp.1.003.554 dibandingkan dengan Rumah Kayu Tipe Kecil $\left(36 \mathrm{~m}^{2}\right)$, Tipe Besar $\left(112 \mathrm{~m}^{2}\right)$ dan Tipe Ekstra $\left(198 \mathrm{~m}^{2}\right)$.

\section{Saran}

1) CV Tumou Pratama tetap melanjutkan dan mengembangkan usaha rumah kayunya, karena usaha tersebut menguntungkan terutama untuk Rumah Kayu Tipe Sedang $\left(70 \mathrm{~m}^{2}\right)$.

2) Untuk pengembangan usaha ke depan maka pengusaha CV Tumou Pratama sebaiknya membuat pencatatan atau pembukuan yang lebih detil lagi, semua komponen biaya dapat terdata dengan baik dan lengkap.

3) Untuk penelitian selanjutnya disarankan agar dapat menghitung keuntungan maksimum dari usaha ini.

\section{DAFTAR PUSTAKA}

Amril. 2003. Analisis Eksistensi Industri Perkayuan Sebagai Sektor Pemimpin (Leading Sector) di Provinsi Jambi. Jurnal Manajemen dan Pembangunan Vol. 02 no. 01 ISSN. Scholar google.co.id.

Kompas. 13 November 2018. Rumah Panggung Tomohon di Ekspor ke 30 Negara.

Rumagit, G. A. J. 1997. Analisis Ekonomi Budaya Pengembangan Industri Rumah Kayu Minahasa. Tesis, Program Pasca Sarjana, Institut Pertanian Bogor. Scholar google.co.id.

Soekartawi. 2006. Analisis Usahatani. UI Press. Jakarta.

Supardi, I. 2003. Lingkungan Hidup dan Kelestariannya.Cetakan Ke-3.PT Alumni. Bandung. 